\title{
Teaching evolutionary biology
}

\author{
Rosana Tidon ${ }^{1}$ and Richard C. Lewontin ${ }^{2}$ \\ ${ }^{1}$ Universidade de Brasília. Brasília, Instituto de Ciências Biológicas, \\ Departamento de Genética e Morfologia, Brasília, DF, Brazil. \\ ${ }^{2}$ Harvard University, Museum of Comparative Zoology, Department of Organismic \\ and Evolutionary Biology, Cambridge, MA, USA.
}

\begin{abstract}
Evolutionary Biology integrates several disciplines of Biology in a complex and interactive manner, where a deep understanding of the subject demands knowledge in diverse areas. Since this knowledge is often inaccessible to the majority of specialized professionals, including the teachers, we present some reflections in order to stimulate discussions aimed at the improvement of the conditions of education in this area. We examine the profile of evolutionary teaching in Brazil, based on questionnaires distributed to teachers in Secondary Education in the Federal District, on data provided by the "National Institute for Educational Studies and Research", and on information collected from teachers working in various regions of this country. Issues related to biological misconceptions, curriculum and didactic material are discussed, and some proposals are presented with the objective of aiding discussions aimed at the improvement of the teaching of evolutionary biology.
\end{abstract}

Key words: education, evolutionary biology, misconception, teaching.

Received: August 8, 2003; Accepted: November 17, 2003.

\section{Introduction}

Evolutionary Biology integrates several disciplines of Biology, and relates biological sciences with other areas of knowledge such as sociology, mathematics and computer sciences (Futuyma, 1999). The famous quotation "Nothing in biology makes sense except in the light of evolution" (Dobzhansky, 1973) has shown itself to be truer each day, considering that extraordinary development in diverse areas, especially molecular and developmental biology, has generated robust and consistent explanations for a variety of questions related to origin and evolution of life.

This panorama is progressively transforming Evolutionary Biology into a complex and interactive science, where a deep understanding of the subject not only demands knowledge in diverse areas of biology, but also of geology, mathematics and philosophy, among others. Such knowledge is often inaccessible to the majority of specialized professionals, including those involved with its transmission: the teachers.

In 1994, the Journal of Research in Science Teaching published a special issue, entitled "The teaching and learning of biological evolution". The editor of that issue stated

Send correspondence to R. Tidon. Universidade de Brasília. Brasília, Instituto de Ciências Biológicas, Departamento de Genética e Morfologia, Caixa Postal 04457, 70919-970 Brasília, DF, Brazil. E-mail: rotidon@unb.br. that it was curious that relatively few studies on the teaching and learning of evolution and related concepts had been published since 1970, while at the same time hundreds of such studies in physics (mechanics) have appeared (Good, 1994). Although the academic community has considerably increased its activity concerning the teaching of evolution, the state of public understanding of evolution is still considered woefully lacking by most researchers and educators (Alters and Nelson, 2002).

In the United States, the situation is more complex and, therefore, education in evolutionary biology is accompanied by with a strong resistance of creationist organizations (Numbers, 1982; Scott, 1997; Antolin and Herbers, 2001), whose influence has been great mainly in those regions with substantial populations of Protestant Evangelicals (Lerner, 2000).

Although Brazil does not have strong creationist traditions, there have been changes in the proportions of the population with different religious orientations (Table 1). The proportion of Catholics is declining as that of evangelicals and of those without any religion grows. The Brazilian Creationist Society (www.scb.org.br), created in 1971, is increasing the number of publications and antievolutionists pamphlets distributed in the country, including the translation of books with totally distorted views of 
Table 1 - Distribution of the Brazilian population (\%) among religions, between 1940 and 2000, according to the demographic census of the Instituto Brasileiro de Geografia e Estatística (IBGE 2000).

\begin{tabular}{lrrrr}
\hline Religion/doctrine & 1940 & 1950 & 1991 & 2000 \\
\hline Catholic & 95.2 & 93.7 & 83.0 & 73.6 \\
Evangelical & 2.6 & 3.4 & 9.0 & 15.4 \\
Without religion & 0.3 & 0.5 & 4.7 & 7.3 \\
Other & 1.9 & 2.4 & 3.3 & 3.7 \\
\hline
\end{tabular}

the evolutionary theory (Flori and Rasolofomasoandro, 2002; Junker and Scherer, 2002).

The scenario of education in Brazil has been the object of reflection by diverse professionals. The Ministry of Education (MEC) developed some programs over the past few years, with the objective of evaluating and improving the quality of institutions of education and didactic materials. National and state research foundations, in partnership with universities, as well as some Brazilian scientific societies, have also developed projects directed at the improvement of the educational conditions. At the annual meeting of the Brazilian Society of Genetics, for example, subjects related to education in genetics and evolutionary biology have been discussed in activities such as "Genetics in the Square", where the exchange of experiences among scientists, students and teachers who take part in basic education is possible.

In 1997, one of us (Tidon) investigated some aspects of the teaching of Evolutionary Biology in Brasilia, by means of the distribution of 110 questionnaires (of which 71 were returned to the investigator) to teachers in Secondary Education in the Federal District. The objective was to identify possible difficulties with which the teachers might be dealing. Although the results obtained in this context must be considered with caution, due to the size of the sample and heterogeneity of Brazil, the main conclusions obtained in this research coincide with data from the remaining portion of the country, obtained by the "National Institute for Educational Studies and Research" (INEP, 1999), and with information collected from teachers working in diverse regions of Brazil.

In this article, some of the main data obtained from the research developed in Brasilia will be presented, pointing to the profile, the conceptions and the main difficulties mentioned by teachers in teaching Evolutionary Biology at the end of Secondary Education. On the basis of these data, and the lines of curricular direction generated by the Ministry of Education, we present some reflections in order to stimulate discussions aimed at the improvement of the conditions of education in this area.

\section{Profile of evolutionary teaching in Brasilia}

The majority of the teachers consulted are young: $74 \%$ are less than 40 years old (62\% of these are under 30$)$.
These data are consistent with those found by INEP (1999) for the country as a whole, which show that for the same period $75 \%$ of the teachers in Secondary Education in Brazil are younger than 44 years old. Regarding to experience, $58 \%$ of the teachers have less than 10 years of didactic experience. The average experience of teachers of Basic Education (including Fundamental and Secondary Education) is 9 years, $75 \%$ of them having taught less than 15 years (INEP, op. cit.). This means that, if they remain in this career, they will still be teaching for many years.

According to the data of INEP, $89 \%$ of the teachers acting in Brazilian secondary education have finished the 3rd degree (college or university). Although all the teachers in the sample have university level education (this proportion in Brasilia is $97 \%$ ), only $82 \%$ of them have studied Evolutionary Biology in college or university, and these consider the knowledge obtained in this area very useful for their teaching activities. Regarding the teaching of Evolutionary Biology, $60 \%$ of those interviewed admit some type of difficulty; the most often reported were the lack of preparation of the teachers, lack of didactic material and lack of time for this material in the curriculum. Most of the teachers $(62 \%)$ consider that the pupils of secondary education are immature and/or do not have a sufficient theoretical basis for understanding evolutionary biology.

The contents of evolutionary biology usually are covered in a few class sessions, at the end of Secondary Education. According to data obtained in Brasilia, 65\% of the teachers provide less than 10 sessions to examine the subject, and generally (59\% of the teachers) these classes are given during the last year of Secondary Education. Considering that more than 200 class sessions of biology are given during three years of secondary education, the portion dedicated to the study of evolutionary biology can be considered hardly significant. This panorama strongly contrasts with the National Curricular Parameters of the MEC (PCN, 2002), which suggests as articulated coverage along the Ecology-Evolution axis, treated historically, with the objective - among others - of understanding the historical-philosophical dimension of scientific production and the character of scientific truth.

One of the items on the questionnaire requested that the teachers evaluate the degree of difficulty in teaching some parts of Evolutionary Biology (Figure 1). As we might expect, the two topics considered "more difficult" were the calculation of gene frequencies and the HardyWeinberg equilibrium. Difficulties in understanding these subjects are always noted in courses of enhancement for teachers. The teaching of population genetics has been given considerable attention in the elaboration of didactic techniques such as the use of buttons of different colors to simulate alleles. The two subjects considered "easier", on the other hand, were the theories of Lamark and Darwin, respectively. This last result is surprising, especially when compared to the answers given to the three last questions on 


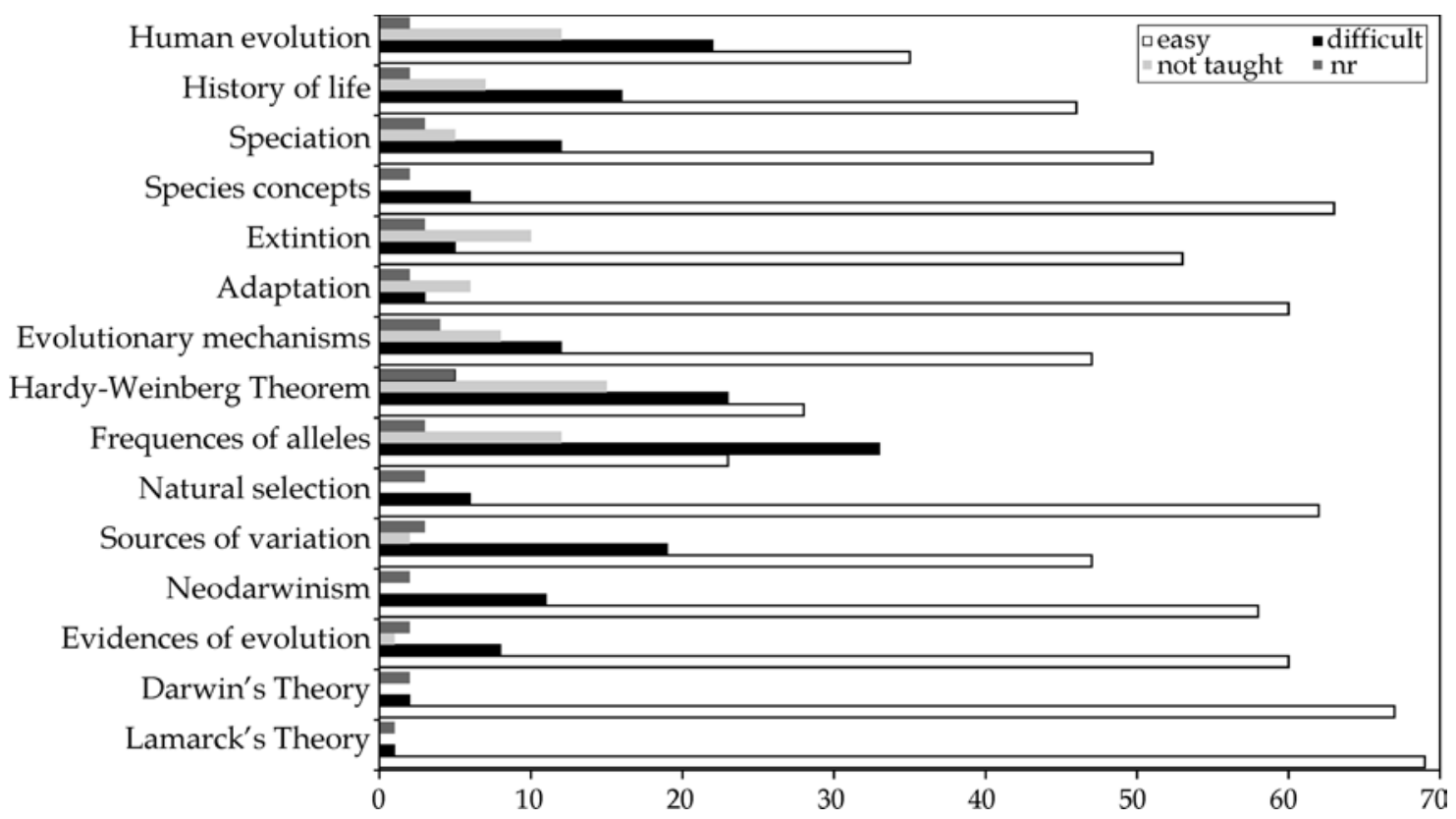

Figure 1 - Evaluation by teachers of the difficulty in teaching various topics in evolutionary biology.

the questionnaire: 1) does biological evolution always produce improvement? 2) has biological evolution any direction?, and 3) does biological evolution occur in an individual? Affirmative answers to these questions were given in, respectively, to $34 \%, 48 \%$ and $41 \%$ of cases, suggesting that some part of the teachers may have Lamarckist conceptions of the evolution of life, even though the majority consider it "easy" to distinguish between the theories of Darwin and Lamarck.

\section{A Generalized Misunderstanding}

Evolution is considered an essential topic that brings to the school a broader perspective on natural phenomena and of the nature of science. However, most, if not all, research has shown that the result of the teaching of evolutionary theories is not generally positive in different parts of the world (Brumby, 1984; Bishop and Anderson, 1990; Aleijandre, 1994; Anderson et al., 2002; Passmore and Stewart, 2002), including Brazil (Bizzo, 1994).

Among the main difficulties in teaching and learning evolutionary biology, are the alternative concepts. Conceptual change teaching recognizes that students enter the courses already having developed explanations of natural phenomena. These explanations are often incompatible with scientific theory, but they may be very difficult to change because they are strongly rooted in student's prior experience and personal attempts to make sense of the world (Bishop and Anderson, 1990). The inventory of alternative conceptions regarding evolution is long and has focused on several subtopics such as natural selection, adaptation, reproduction, and speciation (Anderson et al., 2002). According to Demastes et al. (1995), investigations into student's conceptual frameworks for evolution identified several areas of difficulty in constructing a scientific conception of evolution, including (a) use of adaptation in the individual sense of proximate change, as well as a Lamarckian explanation of adaptation, (b) teleological explanations to describe evolutionary change, and (c) use of fitness as a measure of strength, athletic ability or intelligence.

The understanding of evolution as the process in which species respond to environmental conditions by changing gradually over time leads to the idea that the environment (rather than random processes and natural selection) cause traits to change, that is, that acquired traits can be inherited, and that variability is not important in evolution. Usually this kind of idea is related to the notion of need, i.e., organisms develop new traits because they need them to survive, and the word "adaptation" is used to refer to individuals changing in response to the environment. These conceptions, frequently linked to an ideal of "progress", were recognized in different countries among highschool students (Bizzo, 1994; Demastes et al., 1995), university students (Brumby, 1984; Bishop and Anderson, 1990; Oliveira and Araújo, 1997; Moore et al., 2002), and also teachers (Aleijandre, 1994; Rutledge and Warden, 2000).

Some students ascribe agency when attempting to describe evolutionary processes. Moore et al. (2002) reported some problematic notions held by students, such as adaptative processes that are purposive, even conscious, striving for evolutionary progress and advantage. The authors argued that the background influence of this agency notion presents itself continuously and obtrusively to educators, specifically because agency concepts may hinder 
the understanding of the mechanistic and random processes of natural selection in two ways: first, pre-held concepts of agency may render the scientifically accepted concepts difficult to understand; secondly, agency concepts may form an easy "fall-back position" for learners having trouble with the scientific concepts.

In fact, the history of evolution has been interpreted as a grand progress upward through the "higher" animals toward the emergence of mankind for many of those who accepted evolution. These include Darwin himself in unguarded moments, and even some evolutionary biologists who have taken some of the qualities we most prize in ourselves, such as intellect or empathy, as criteria of progress, and, quite ignoring the innumerable lineages that have not evolved at all in these directions (Futuyma 1998, p. 699).

Originally, the very word "evolution" meant an unfolding or unrolling, and before Darwinian evolution became widely accepted the Scala Naturae was one of the most enduring and powerful of Western concepts: all living things were arranged on a linear scale surmounted by the human species. This transformational metaphor of unfolding, however, was abandoned considering that the process of evolution does not have a goal, and that evolutionary mechanisms have a strong stochastic component. Darwinism introduced the model of trial and error as a fundamental description for the historical processes, and the neoDarwinian picture of evolution is then a three-fold process: variation, trial and error, and assimilation. Unfortunately, as a description of the actual process of organic evolution, this metaphor is also both incomplete and inaccurate (Lewontin, 1982).

First, the process of natural selection cannot be shown to maximize or even increase the average reproductive fitness of organisms as a general rule. In fact, it is easy to construct biologically reasonable cases in which natural selection actually decreases any of these measures of "adaptation". Mendelian segregation of genes in sexually reproducing organisms, and frequency-dependent fitness, for example, are important sources that may reduce the fitnesses (Lewontin, 1982). Moreover, pleiotropic effects of genes, linkage and random chance may also promote the establishment of a non adaptative characteristic. Second, the notion that the environment is a static scenario to which the species adapt, although easily understandable, is wrong (Lewontin, 2000, for a Portuguese version, see Lewontin, 2002). In fact, it is impossible to describe an environment except by reference to organisms that interact with it and define it. The environment of an organism is a juxtaposition of various parts of the physical world that is structured by the life activities of that organism. Organisms and environment are dialectically related. That is, there is no organism without an environment and there is no environment without an organism.

It is very important that the relations between organism and environment are addressed from the first years of science studies, since its complexity requires time for the pupil to understand them appropriately. The comprehension of these relations, besides being prerequisite for the understanding of biological evolution, is basic for the formation of citizens' responsibility for the environment, of which they feel themselves an integral part, and not only a passive and alienated object.

The question of language is widely discussed in the literature. Both film and written accounts, in an attempt to simplify concepts for the lay public, often use language that tends to reinforce previous misconceptions. The prevalence of vernacular misconceptions is certainly not surprising, since many scientific words like "adapt", "adaptation" and "fitness" are used in day-to-day language but carry meanings that are quite different from their meanings in the context of evolution (Bishop and Anderson, 1990; Alters and Nelson, 2002). The figurative language, typical of abstract conceptions, contrasts with the more precise language of concrete specificity, which is less prone to figurative license. While expert biologists easily recognize the shift from one frame of reference to another, it is possible that novices do not, and that this may be one (of many) reasons why the particular conceptual confusions noted above persist (Moore et al., 2002).

In conclusion, the pre-conceptions and difficulties mentioned above over-simplify the complexity of nature, and seem to be widely spread in several parts of the world, probably because these naive ideas seem logical and easy to understand, i.e., it would be much neater if organisms could simply acquire those features necessary for survival, but nature does not operate in this manner (Bishop and Anderson, 1990).

\section{Didactic Material and Curriculum}

The unsuitability of the didactic materials available to them was mentioned by the teachers in Brasilia as one of the difficulties faced by them. Several authors have assessed how textbooks deal with topics related to evolutionary biology in several parts of the world, and found that, in many cases, the textbooks analyzed not only fail to address student's difficulties, but also do not even constitute a good resource for traditional teaching (Aleixandre, 1994; Swarts et al., 1994; Jeffery and Roach, 1994). In the US, where the exposition of evolutionary biology theory in secondary-level biology textbooks has been adversely affected for many years due to the influence of a nonscientific segment of public opinion, a marked increase has occurred in the role played by evolution in the generation of textbooks published during the 1990s (Moody, 1996). In Brazil, the "National Program of Didactic Books", led by the Ministry of Education, led to a significant improvement in the quality of books used in Fundamental Education (Bizzo, 2000). However, the material used in Secondary Education has still not been the object of extensive analysis, even though some content of evolutionary biology has already been ana- 
lyzed separately (Bizzo, 1994). A deeper analysis of what occurs in Brazil in secondary education material would be extremely opportune, since the knowledge of the qualities and failures of textbooks currently used would help publishing companies to improve them.

The covering of Biology in the curriculum seems to be a problem not only in Brazil, but in other countries as well. According to Barbera et al. (1999), evolution and evolutionary theory has never been covered adequately in Spanish curricula, even in the newest curriculum; analyses performed in the US showed that one-third of US states have unsatisfactory standards for teaching evolution (Lerner, 2000, but see also Skoog and Bilica, 2002). In Brazil, the curricular parameters developed by the Ministry of the Education recommend that the areas of ecology and evolution serve as "trans-disciplinary subjects" that permeate all the other contents of biology. However, in the practice, evolutionary biology is generally taught at the end of 3 rd year of secondary education, for which reason such knowledge often does not reach the classroom.

Another problem related to curriculum is the sequence in which the contents are presented to pupils. It is widely acknowledged that evolution and Darwinian model of natural selection play a central role in modern biology. At the same time, it has been suggested that the topic should be dealt with in the later grades, owing to the difficulties encountered, for instance, by the general lack of a sound knowledge of related topics such as genetics. The contradiction between the importance of the issue and its difficulties has created a controversy in Spain (Aleixandre, 1994) and has also been already discussed in a Brazilian context (Bizzo, 1994). Certainly, this is an important issue interlaced with those we had previously reviewed.

\section{Some Proposals}

A concern with the quality of education in evolution exists in several parts of the world, including Brazil. Thus, there exist diverse proposals for dealing with the previously discussed problems, some of which will be presented below, with the objective of aiding discussions aimed at the improvement of the teaching of evolutionary biology.

There are three complementary approaches to this program that in certain respects have already been in progress in Brazil, but are in different stages of maturity. The first is the continuous training of school teachers, by supporting courses and workshops that will be rewarded by professional advancement. The second relates to the revision and reinforcement of the curricula of Sciences, and Biology in particular, aimed at improving, in a practical way, the curricular program of the Brazilian Ministry of Education. Finally, the continuity of the National Program of Textbooks is of utmost importance, with the inclusion of the analysis of books used in the secondary education.

The courses planned for the training of school teachers would have two main objectives. First, in terms of contents, the formation of teachers must include the identification of their previous conceptions, the conceptual change needed, and the update of that knowledge. On the other hand, it is necessary to provide the instruments of instruction for these teachers in terms of strategies for teaching, such as the question of the didactic material, of the language, and of the time available in classroom for dealing with the discipline.

The recognition of the misconceptions of teachers about the evolutionary process is necessary, given the strong possibility that several of them, unconsciously, use Lamarckist reasoning in explaining the biological evolution. That is, for those who want to change student's naive concepts, the first step is to understand them (Bishop and Anderson, 1990). In order to assess the student's understanding of natural selection, Anderson et al. (2002) developed the "Conceptual Inventory of Natural Selection", a comprehensive 20 -item multiple choice test that employs common alternative conceptions as contrasts. An activity like this, applied on the first day of the course, could be the starting point for recognizing the misconceptions of the teachers and, at the same time, it would illustrate something that they could develop later in their own classrooms.

Suggestions for teaching strategies usually have been attempts to promote conceptual change (Jensen and Finley, 1995), and the basic conditions required for this kind of change were outlined by Posner et al. (1982, apud Jensen and Finley, 1995). The first condition is met when the learner becomes dissatisfied with his or her current understanding of some event. The students should experience a form of cognitive disequilibrium, in that they can not rationally explain some event with their current understanding. The second condition requires that the students have a meaningful understanding of at least some newly presented information. The third condition is met when the students are able to judge the new information as plausible. If the new information does not achieve some degree of fit into a student's existing understanding, it is likely to be rejected. The fourth and final condition is that the students must be able to use the new understanding in fruitful ways. After all four conditions have been met, a student hopefully has learned that the new understanding has more utility than the old and is thus worth retaining.

Attempts at conceptual change have usually been based on instructional materials, discussions and the use of historically valid ideas (Bizzo, 1994). Jensen and Finley (1995) developed and tested a very interesting, historically rich, teaching technique for biological evolution, and their data show that if instruction recapitulates events in the development of the Darwinian theory of evolution by natural selection in a way that meets the conditions for conceptual change, then students replace their initial conceptions with a more Darwinian conception. This strategy is totally in accordance with the recommendations of MEC (PCN, 1997), where we read: The education in Natural Sciences provides 
room for the expression of spontaneous explanations by the pupils, and for those derived from several systems of explanations. The opposition and evaluation of different explanations favors the development of a reflexive, investigative and critical posture, of no- a priori acceptance of ideas and information. It makes possible the perception of the limits of each explicative model, including the scientific ones, leading to the construction of autonomy of thought and action.

It is very important that, in the training of teachers, attention is paid to the use of the language (Moore et al., 2002). Teachers and students usually construct a code among themselves that is established in the classroom, in such a way that the direct participants seem to understand each other, regarding the plasticity of language used, but which would not be clear to outsiders. Bizzo (1994) detected this system of shared meanings in the context of the classroom in relation to evolutionary discourse. So, if the teacher has a clear understanding of the difference between the meanings of some scientific terms in relation to their daily use, then he or she can make it possible for the pupils to capture correctly the meaning of such terms as "adaptation" and "fitness". A good suggestion for exploring this subject is the essay by Gould (1977) entitled "Darwin's Dilemma: the Odyssey of Evolution" in which the meanings of the term "evolution" in science and daily life are compared (for a Portuguese version, see Gould, 1992).

The question of the time devoted to teaching evolution, as well as the distribution of its contents in various places in the curriculum, is perhaps a little more complicated. The recommendations from the MEC for secondary education (PCN, 2002) emphasize the importance of integrating knowledge from several biological areas, since the perception of the basic unit of the life, recognizing its vast diversity, has a complexity without parallel in all science... it is not an academic luxury, but a presupposition for a minimum understanding of the mechanisms of heredity and even of contemporary biotechnology, without which one can not understand and make judgments on paternity tests by the analysis of the DNA, the cloning of animals, or the way in which certain viruses produce imunodeficiencies. However, it is difficult to reach these objectives, since there are no concrete proposals for the organization and the treatment of the curricular contents of evolutionary biology at each level of education.

The elaboration of a curricular plan, or a part of it, must be concerned with the continuity of learning. Each successive experience must have its origin in the preceding one, but deepening and extending the approach of the issues treated. Box 1 (adapted from Lerner, 2000) presents some

\section{Essentials of good standards (modified from Lerner, 2000)}

What is needed to provide the student with a good understanding of the life sciences and the unifying role of evolution? At the primary grade levels, standards should focus on those basic facts and ideas of evolution that can later be incorporated into broader world views. At the Fundamental level (age 7-10), students should be expected to understand that all living things reproduce; that offspring are similar to but not exactly like their parents; that offspring have to grow up (or change) before reproducing themselves; that there are several levels of adjustment between individuals, or species, and their environment (in some cases there seems to be a fit, but not in others); and that the Earth is more than four billion years old, allowing large amounts of time for biological as well as geological evolution.

At higher grade levels (ages 11-14) these ideas can be developed into an understanding of the nature of competition for survival between and within species; the consequence of the fact that not all offspring live long enough to reproduce; the limitation imposed on the number of offspring that survive by such environmental factors as the availability of food and water, predators and climate; the variability among individuals that leads to differential survival in a particular environment; the specialization of species to different kinds of environments, and the impact of environmental change on the stability of those niches; the underlying role of genetic variation that results from sexual reproduction and random mutation; and the non-random way that natural selection operates on the existing population despite the many random factors that determine the survival of any individual.

At the secondary level (age 15-18) these ideas can be unified, and such concepts as genetic drift, sexual selection and other significant mechanisms can be introduced. Coevolution and the complex interactions of ecosystems are important applications of the basic concepts. The human species should be considered as an integral part of the environment, and responsible for several of the changes that are causing ecological disequilibria in different parts of the world.

The magnitude of the geological/evolutionary time scale is so different from the time scales of everyday life that it is difficult to grasp, and must be introduced with care. The fact that the same general time scale underlies both geological and biological evolution is an important link between the two sciences.

In parallel to these macroscopic concepts, the underlying microscopic mechanisms must be introduced at suitable grade levels. These include the relation of genotype to phenotype, DNA as an information carrier, the expression of DNA in protein synthesis and the implications thereof at the various levels of organization from organelles through cells, tissues, organs and individual organisms, to populations. It is also important to teach that biological evolution does not take place in a vacuum. The biota and the nonliving parts of the Earth coexist with and influence each other. Therefore, the facts and, subsequently, the theoretical structure of geological evolution must be introduced in parallel with biological evolution. Similarly, the Earth is part of the Solar System and the Solar System part of a hierarchy of still larger structures, up to the Universe as a whole. The student should be empowered to view the history of the Universe, from the general cosmological picture down to the smaller scales characterizing the Earth and its smaller elements, from a unified perspective. 
suggestions for the distribution of the contents of evolutionary biology through the curriculum, and can serve as starting point for reflections on the subject.

In relation to the sequence of the contents in the curriculum, historical question should be taken in consideration. We would do well to heed Bizzo (1994), who warns of "social reconceptualizations" in evolution education. Myths and connotations evolve from who is communicating, what their intended message is, and the passage of time (Zook, 1995). Perhaps a more reflective historical approach in the classroom would help the student's understanding of evolution.

Formal education both trains the nation's work force in each of the areas of specialized knowledge and methodology on which society depends, and trains an informed citizenry that can make reasoned decisions and adapt to change. As science and technology change our world at an ever-increasing pace, it becomes steadily more important for people to understand and use information from the sciences, including biology (Futuyma, 1999; see Futuyma 2002 for a Portuguese version of this text).

According to the National Curriculum Parameters for Brazilian Secondary Education (Ministry of Education), the teaching of Biology it is essential for developing attitudes and values that are germane to the relationships among human beings, between human beings and the environment, and between human beings and knowledge, thus contributing to an education that will develop and train sensitive and supportive individuals, as well as citizens who are aware of the processes and regularities of the world and of life: individuals and citizens who are able to carry out practical actions, form judgments and make decisions. Certainly, the teaching of evolutionary biology would contribute to these goals.

\section{Acknowledgments}

We are grateful to E. Romano, D. Ayres, R.P. Silva and especially C. Ligocki for their stimulus and help in the data collection, and to Conselho Nacional de Desenvolvimento Científico e Tecnológico (CNPq), Universidade de Brasília and Harvard University for providing the necessary conditions for this work.

\section{References}

Aleixandre MPJ (1994) Teaching evolution and natural-selection - a look at textbooks and teachers. Journal of Research in Science Teaching 31:519-535.

Alters BJ and Nelson CE (2002) Perspective: teaching evolution in higher education. Evolution 56:1891-1901.

Anderson DL, Fisher KM and Norman GJ (2002) Development and evaluation of the conceptual inventory of natural selection. Journal of Research in Science Teaching 39:952-978.

Antolin MF and Herbers JM (2001) Perspective: evolution's struggle for existence in America's public schools. Evolution 55:2379-2388.
Barbera O, Zanon B and Perez-Pla JF (1999) Biology curriculum in twentieth-century Spain. Science Education 83:97-111.

Bishop BA and Anderson CW (1990) Student conceptions of natural selection and its role in evolution. Journal of Research in Science Teaching 27:415-427.

Bizzo NMV (1994) From down house landlord to Brazilian highschool-students - what has happened to evolutionary knowledge on the way? Journal of Research in Science Teaching 31:537-556.

Bizzo NMV (2000) Falhas no ensino de ciências. Ciência Hoje 159:26-31.

Brumby MN (1984) Misconceptions about the concept of natural-selection by medical biology students. Science Education 68:493-503

Demastes SS, Settlage J and Good R (1995) Students conceptions of natural-selection and its role in evolution - cases of replication and comparison. Journal of Research in Science Teaching 32:535-550.

Dobzhansky T (1973) Nothing in Biology makes sense except in light of evolution. American Biology Teacher 35:125-129.

Flori J and Rasolofomasoandro H (2002) Em busca das origens: evolução ou criação? Editorial Safeliz, Madrid, 342 pp.

Futuyma DJ (1998) Evolutionary Biology. Sinauer Associates, Inc., Sunderland, MA, 763 pp.

Futuyma DJ (1999) Evolution, science and society: evolutionary Biology and the national research agenda. The State University of New Jersey, New Brunswick, NJ.

Futuyma DJ (2002) Evolução, ciência e sociedade. JS Morgante (ed) Available on-line by the Brazilian Society of Genetics. URL: http://www.sbg.org.br.

Good R (1994) Evolution education - an area of needed research. Journal of Research in Science Teaching 29:1019-1019.

Gould SJ (1977) Darwin's dilemma: the odyssey of evolution. Ever since Darwin: reflections in natural history, Norton, New York, pp 34-38.

Gould SJ (1992) Darwin e os grandes enigmas da vida. 2nd edição. Editora Martins Fontes, São Paulo, 274 pp.

IBGE (2000) Pesquisa nacional por amostra de domicílios. Senso demográfico 2000. Instituto Brasileiro de Geografia e Estatística (www.edeus.org/port/IBGEBR.htm).

INEP (1999) Perfil do magistério da educação básica: censo do professor 97. Instituto Nacional de Estudos e Pesquisas Educacionais. Ministério da Educação, Brasilia, 150 pp.

Jeffery KR and Roach LE (1994) A study of the presence of evolutionary protoconcepts in pre- high-school textbooks. Journal of Research in Science Teaching 31:507-518.

Jensen MS and Finley FN (1995) Teaching evolution using historical arguments in a conceptual change strategy. Science Education 79:147-166.

Junker R and Scherer S (2002) Evolução - um livro didático crítico. Sociedade Criacionista Brasileira, Brasília, 328 pp.

Lerner LS (2000) Good and bad science in US schools - one-third of US states have unsatisfactory standards for teaching evolution. Nature 407:287-290.

Lewontin RC (1982) Organism and environment. In: Plotkin HC (ed) Learning, development, and culture. John Wiley \& Sons Ltd., pp 151-170.

Lewontin RC (2000) The triple helix: gene, organism, and environment. Harvard University Press, Cambridge, MA, $160 \mathrm{pp}$. 
Lewontin RC (2002) A tripla hélice - gene, organismo e ambiente. Companhia das Letras, São Paulo, 144 pp.

Moody DE (1996) Evolution and the textbook structure of Biology. Science Education 80:395-418.

Moore R, Mitchell G, Bally R, Inglis M, Day J and Jacobs D (2002) Undergraduates' understanding of evolution: ascriptions of agency as a problem for student learning. Journal of Biological Education 36:65-71.

Numbers RL (1982) Creationism in 20th-Century America. Science 218:538-544.

Oliveira DL and Araújo AM (1997) Um caminho epistemológico para compreender concepções de evolução. Anais do VI Seminário Nacional de História da Ciência e da Tecnologia: 344-349, Sociedade Brasileira de História da Ciência, Rio de Janeiro, Brazil.

PCN Ensino Fundamental (1997) Parâmetros Curriculares Nacionais do Ensino Fundamental: ciências naturais. Secretaria da Educação Fundamental, Ministério da Educação, Brasília, $136 \mathrm{pp}$.

PCN Ensino Médio (2002) Parâmetros Curriculares Nacionais do Ensino Médio Parte III - ciências da natureza, matemática e suas tecnologias. Secretaria da Educação Média e Tecnológica, Ministério da Educação, Brasília, 144 pp.

Passmore C and Stewart J (2002) A modeling approach to teaching evolutionary biology in high schools. Journal of Research in Science Teaching 39:185-204.

Rutledge ML and Warden MA (2000) Evolutionary theory, the nature of science and high school biology teachers: critical relationships. American Biology Teacher 62:23-31.

Scott EC (1997) Antievolution and creationism in the United States. Annual Review of Anthropology 26:263-289.

Skoog G and Bilica K (2002) The emphasis given to evolution in state science standards: a lever for change in evolution education? Science Education 86:445-462.

Swarts FA, Anderson OR and Swetz FJ (1994) Evolution in secondary-school Biology textbooks of the PRC, the USA, and the latter stages of the USSR. Journal of Research in Science Teaching 31:475-505.

Zook D (1995) Confronting the evolution education abyss. Journal of Research in Science Teaching 32:1111-1120.

Editor: João S. Morgante 